\title{
Persistent megalocystic ovaries after ovarian hyperstimulation syndrome in a postpartum patient with polycystic ovarian syndrome: a case report
}

\author{
Jinghua Shi ${ }^{1}$, Ren Xinyu ${ }^{2}$, Tian Qinjie ${ }^{1}$, Sun Aijun ${ }^{1}$ and Rong Chen ${ }^{1 *}$
}

\begin{abstract}
Background: Ovary enlargement is common in controlled ovarian stimulation, which could continue several months during a successful pregnancy. However, persistent megalocystic ovaries 3 years after ovarian hyperstimulation syndrome (OHSS) were rare. Here we will present you the case and treatment as well as discuss the probable etiology.

Case presentation: A 34-year-old woman with polycystic ovarian syndrome (PCOS) and a history of infertility presented to the Department of Obstetrics and Gynecology at Peking Union Medical College Hospital with abdominal pain and persistently enlarged ovaries 36 months after OHSS. Enlarged ovaries were evaluated with ultrasonography and serum tests. Diagnostic laparoscopic surgery with detorsion and drainage followed by GnRHa treatment was performed. Symptoms and ovarian size evaluated by vaginal ultrasound were the main outcome measures. The patient was discharged from the hospital 5 days after surgery without any remarkable complications. Both ovaries recovered to almost normal after a monthly injection of GnRHa for 3 months.

Conclusions: Ovarian enlargement may persist for a long time in patients with severe OHSS even after sex hormone levels and ovarian functions return to normal. Long term follow-up is necessary and ovarian torsion should be suspected when accompanied by abdominal pain. Acupuncture plus GnRHa treatment may be an effective way for these cases.
\end{abstract}

Keywords: Persistent megalocystic ovaries, Ovarian hyperstimulation syndrome, Polycystic ovarian syndrome, Ovarian torsion

\section{Background}

Ovarian hyperstimulation syndrome (OHSS) is an excessive response to controlled ovarian hyperstimulation during treatment cycles used for assisted reproduction technology (ART). Moderate OHSS occurs during 3-6\% of all cycles, whereas the severe form occurs during $0.1 \%$ of all cycles [1]. For women at high risk for OHSS, this incidence approaches 20\% [2]. Conditions associated with a higher risk of OHSS include young age, low body mass index, polycystic ovarian syndrome (PCOS), higher doses of exogenous gonadotropins, high absolute or

\footnotetext{
* Correspondence: chenrongpumch@163.com

${ }^{1}$ Department of Obstetrics and Gynecology, Peking Union Medical College Hospital (PUMCH), Peking Union Medical College, Chinese Academy of Medical Science, Beijing 100730, People's Republic of China

Full list of author information is available at the end of the article
}

increased rates of serum estradiol $\left(E_{2}\right)$ levels, and previous OHSS [3].

Early-onset OHSS occurs within 9 days after oocyte retrieval and will typically resolve within 7 days if no pregnancy occurs; however, late-onset OHSS appears 10 days after oocyte retrieval [4]. When pregnancy is maintained, symptoms of luteal cysts usually resolve gradually within 1-2 months and rarely persist until the 5th month of gestation [5].

We describe a case of persistent bilateral megalocystic ovaries in a patient with PCOS who became pregnant following in vitro fertilization (IVF). Large ovarian cysts persisted throughout the pregnancy and more than 2 years after delivery. To our knowledge, this is the first case of enlarged ovaries that persisted 36 months after OHSS.

(c) The Author(s). 2018 Open Access This article is distributed under the terms of the Creative Commons Attribution 4.0 International License (http://creativecommons.org/licenses/by/4.0/), which permits unrestricted use, distribution, and reproduction in any medium, provided you give appropriate credit to the original author(s) and the source, provide a link to the Creative Commons license, and indicate if changes were made. The Creative Commons Public Domain Dedication waiver (http://creativecommons.org/publicdomain/zero/1.0/) applies to the data made available in this article, unless otherwise stated. 


\section{Case presentation}

A 34-year-old woman (gravida 4, para 1, abort 3) presented to our clinic for pelvic pain and enlarged ovaries at PUMCH (Peking Union Medical College Hospital) with a 5-day history of left lower quadrant abdominal pain. The pain was atypical, without nausea, vomiting, dysuria, or diarrhea. Her last menstrual period was 2 weeks prior to presentation. There were palpable, cystic, solid masses on both sides in the lower quadrant. Laboratory tests revealed a white blood cell count of $22.9 \times 10^{9} / \mathrm{L}$, granulocyte rate of $80.6 \%$, and a normal $\beta$-human chorionic gonadotropin $\left(\beta\right.$-hCG) level. She had a transient fever of $37.9{ }^{\circ} \mathrm{C}$; therefore, antibiotics was administered for 4 days. When she came to our hospital, pelvic pain was relieved. Ultrasound imaging and computed tomography (Fig. 1) revealed that both the ovaries were enlarged $(\geq 10 \mathrm{~cm})$ with multiple follicles inside. Serum hormone levels were normal: follicle -stimulating hormone (FSH), $2.38 \mathrm{IU} / \mathrm{L} ; \mathrm{E}_{2}, 46.85 \mathrm{pg} / \mathrm{mL}$; progesterone $(\mathrm{P}), 0.35 \mathrm{ng} / \mathrm{mL}$; testosterone $(\mathrm{T}), 0.54 \mathrm{ng} / \mathrm{mL}$; luteinizing hormone (LH), <0.2 IU/L; prolactin (PRL), $7.44 \mathrm{ng} / \mathrm{mL}$.Dehydroepiandrosterone (DHEA), $497.5 \mu \mathrm{g} / \mathrm{dL}$ and 24-h urinary-free cortisol (UFC), $165.24 \mu \mathrm{g}$ were slightly higher than normal. Adrenal ultrasound, serum thyroidstimulating hormone (TSH)/free thyroxine (FT4), thyroxine (T4) and hypothalamic-pituitary magnetic resonance imaging revealed no abnormality. The concentration of tumor marker CA125 was $365.7 \mathrm{U} / \mathrm{mL}$; therefore, a malignant tumor could not be excluded.

Before presentation, she was diagnosed with PCOS and underwent several attempts of ovulation induction and intrauterine insemination. After these failed, she underwent IVF with Marvelon (N.V. Organon, Oss, The Netherlands) and GnRHa stimulation. A combined estrogen and progesterone pill (Marvelon; N.V. Organon) was administered from day 5 of the previous cycle, and $1.2 \mathrm{mg}$ triptorelin embonate (Diphereline; Ipsen Pharma Biotech,

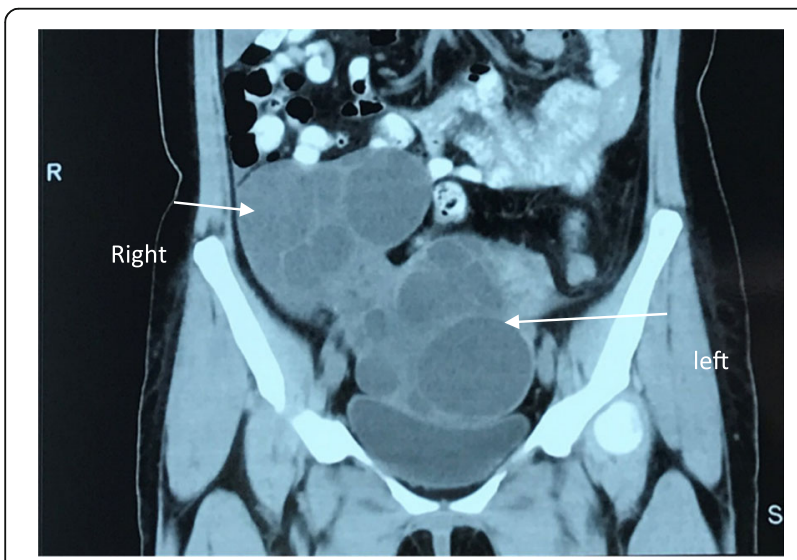

Fig. 1 Computed tomography (CT) scan of the patient. CT showed bilateral enlarged ovaries with multiple septations in abdomen and pelvis
France) was injected intramuscularly on day 16 of taking Marvelon. Stimulation with recombinant follicle-stimulating hormone (Puregon; N.V.Organon) was started subcutaneously after 16 days' down-regulation. Human chorionic gonadotropin (HCG) 5,000 IU was injected when the maxium follicle diameter reached $20 \mathrm{~mm}$. The IVF procedure was performed at another center; therefore, details of estrogen and follicle development could not be traced. Transvaginal oocyte retrieval was uneventful and yielded 24 mature oocytes. Two blastocysts were transferred 4 days later. The patient had severe OHSS 10 days after oocyte retrieval, for which paracentesis was performed three times, with an average of $1,500 \mathrm{~mL}$ abdominal effusion drained each time. She was also suspected to have vein thrombosis of the right lower limbs. The patient became pregnant, and the follow-up was performed at another center. Throughout her perinatal examinations, both the ovaries did not become smaller. The patient delivered a healthy newborn via cesarean at term, a biopsy of the enlarged ovary was performed with benign pathology. No intervention was performed due to the expectation that the hyperstimulated ovaries would shrink during the postpartum period, at the same time she was concerned about the side-effects of those medicines in lactation. Her menstrual period resumed 14 months after delivery, and the child was weaned from breastfeeding at 24 months. However, the size of both the ovaries were still not reduced by then. Three months of oral contraceptives (Marvelon; N.V. Organon) were prescribed.

After admission, she underwent laparoscopic surgery to determine the cause of the persistent enlarged ovaries as well as pain. During laparoscopy, we found a large, torsed, congestive left ovary and a torsed, congestive, ipsilateral fallopian tube. The contralateral adnexa were enlarged but had a normal color. Both ovaries measured approximately $10 \times 12 \mathrm{~cm}$, kiss-forming, were closely stuck together. There were minimal ascites in the abdominal cavity. The omentum majus was adhered to and laid over the left ovary. Laparoscopic detorsion followed by left ovary biopsy and bilateral ovarian acupuncture were performed (Fig. 2). Histopathological examination (Fig. 3) revealed localized congestion and necrosis of the ovary that underwent biopsy, with no associated lesions. Ovary puncture liquid showed elevated $\mathrm{E}_{2}(2,078 \mathrm{pg} / \mathrm{mL})$ and decreased FSH $(0.3 \mathrm{IU} / \mathrm{L})$ and LH $(<0.2 \mathrm{IU} / \mathrm{L})$. The postoperative course was uneventful.

The patient was discharged the following week and received GnRHa $3.75 \mathrm{mg}$ for 3 months. The ovaries shrank somewhat during the first month (left ovary, $5.8 \times 5.1 \mathrm{~cm}$; right ovary, $9.3 \times 6.3 \mathrm{~cm}$ ). Four months after surgery, she underwent an ultrasound scan that found slightly enlarged ovaries with multiple follicles (left ovary, $6.5 \times 4.7 \mathrm{~cm}$; right ovary, $4.1 \times 3.0 \mathrm{~cm}$ ). She did not feel any discomfort; therefore, she was advised to return 6 months later with no further treatment. 

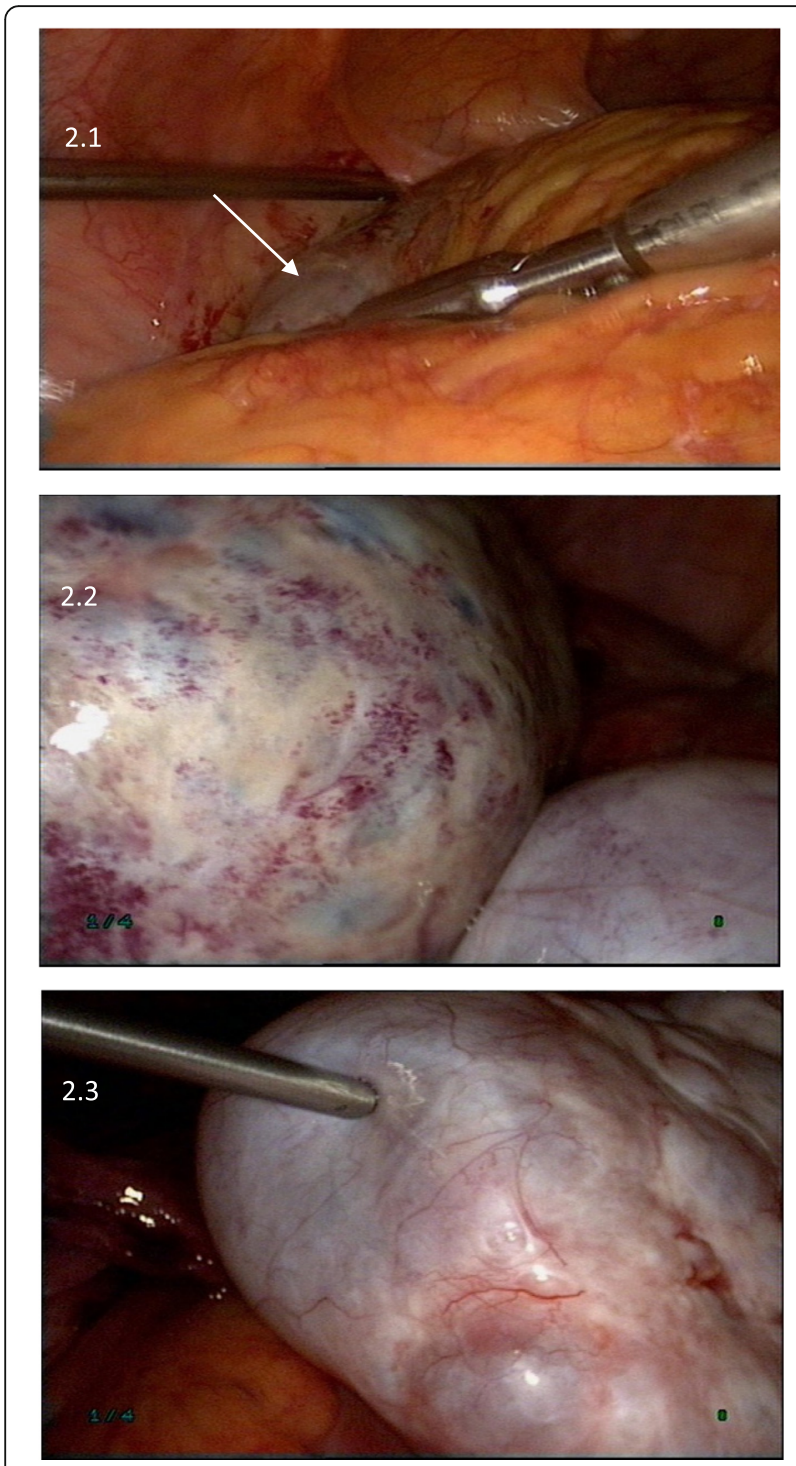

Fig. 2 Appearance of ovaries in surgery. Laparoscopic surgery showed the omentum majus adhering to the left ovary (arrow) which was ischemic caused by ovarian torsion with a maximum diameter of $10+\mathrm{cm}$ (2.1). Both adnexae formed "kissing ovaries" (2.2).The right ovary, measuring about $10 \mathrm{~cm}$ was multinodulated with yellow serous fluid (2.3)

\section{Discussion and conclusions}

\section{Mechanism of ovarian enlargement}

Ovarian enlargement secondary to hyperstimulation is common, especially for PCOS with enlarged ovaries at baseline. According to the Rotterdam criteria, PCOS itself is defined as enlarged ovary with a follicle number of $\geq 12$ per ovary and/or an ovarian volume of $>10 \mathrm{~mL}$ in at least one ovary [6]. During ovulation induction, multiple small follicles grow under hormone stimulation and hCG stimulates the ovaries to continue to grow. Pregnant women are continuously exposed to endogenous hCG. Most ovarian enlargement with multiple follicular and lutein cysts

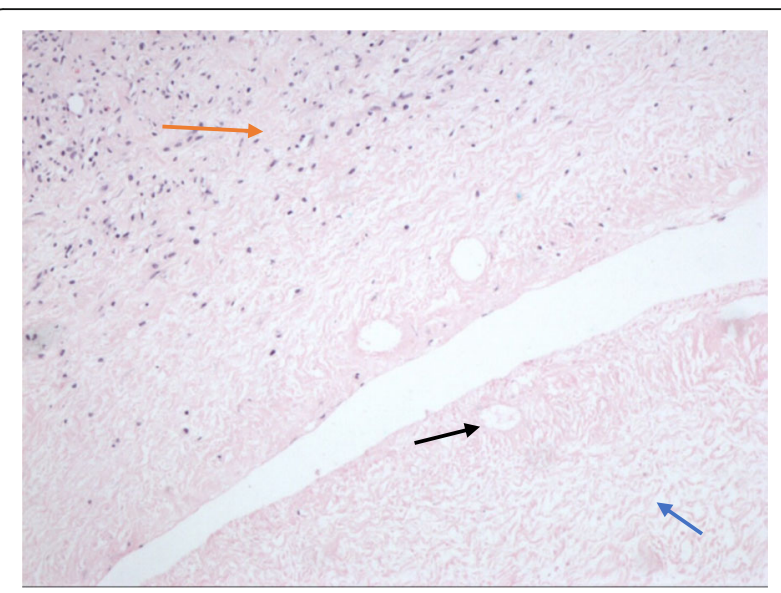

Fig. 3 Histology of the tissue ( $\times 100)$. Detailed legends: the upper left part of the figure showed the survival of the ovarian cortex with short-fusiform and wavy cells ( $\longrightarrow$ ), while the lower right coagulation necrosis, uniform red staining and nucleus lysis $(\longrightarrow$ ), but the organizational structure could be seen vaguely. Necrotic cavities $(\longrightarrow$ ) in the necrosis were the remnants of small blood vessels

persists for a longer period (until the second trimester), because hCG starts to decline to 40,000 IU/L at 20 weeks of gestation. Renal and hepatic functions, which are normal in ordinary controlled ovary hyperstimulation, might altered in sever OHSS and disturb the hormone metabolism [7]. There are many other benign or malignant tumors that need to be differentiated, such as hyperreactio luteinalis, theca lutein cysts, teratoma, endometriosis cyst, mucinous cystadenoma, and others [8]. However, cases of persistent megalocystic ovaries existing for a long time after IVF are rarely reported, and the possible mechanism is unknown.

\section{Indication for exploratory laparoscopy}

Ovarian torsion, the fifth most common gynecological emergency, is defined as the partial or complete rotation of the ovarian vascular pedicle. It causes obstruction of the venous outflow and arterial inflow. It is uncommon for an ovary of normal size to become twisted, but enlarged ovaries are prone to torsion. Pregnant patients are reported to have a $1 \%$ increased risk of ovarian torsion compared to nonpregnant patients. The incidence of ovarian torsion after IVF treatment is rare, ranging from 0.08 to $0.13 \%$ [9]. However, when torsion occurs during pregnancy, symptoms are less atypical, and the decision regarding whether to perform exploratory laparoscopy is difficult. Symptoms like lower abdominal pain, tenderness with a palpable mass, nausea, vomiting, low-grade fever, and leukocytosis are not significant. Ovarian enlargement secondary to IVF is usually bilateral, but torsion rarely occurs on both sides. Therefore, chronic partial torsion might be missed in some cases when clinical follow-up is used rather than surgery. 
The best treatment for ovarian torsion is early diagnosis and prompt surgical intervention. The ovary is untwisted to restore the blood supply, and color changes are observed for 10-15 min. Cystectomy or oophorectomy of the torsed ovary is based on the degree of ischemia and necrosis. Laparoscopic surgery is preferred [10], because it results in less postoperative pain, shorter hospital stays, reduced adhesion formation, and a faster return to normal diet and work. Losing ovary due to a delayed diagnosis in an infertile woman is the worst consequence [11].

\section{Treatment of persistent megalocystic ovaries}

Ling et al. [12] reported a case of persistent megalocystic ovaries during cesarean delivery for a PCOS patient with a pregnancy induced by IVF. The megalocystic ovaries persisted after delivery; therefore, the patient underwent surgery during which biopsies were performed for both ovaries. The histopathological results indicated follicular cysts. Alptekin et al. [13] reported large ovaries during cesarean delivery for a patient without OHSS but who had undergone IVF. However, the uterus and ovaries returned to normal 4 weeks later. Ours is the longest reported case of megalocystic ovaries. There has been no report of or guidance regarding the treatment of persistent megalocystic ovaries lasting such a long time in IVF patients.

The team finally chose the puncture and GnRH agonist protocol based on the high level of hormones in the cystic fluid. Although these hormones were not increased in the blood, the $\mathrm{E}_{2}$ levels were quite high in the follicles. The cumulative effect of such high hormone levels in so many cysts might have an important role in maintaining enlarged ovaries. GnRH agonists [14] have decreased luteotropic effects and alter the expressions of VEGF, VEGF receptor-1, and VEGF receptor-2; they have also been shown to be effective for preventing OHSS in high-risk patients. Both ovaries shrank somewhat after surgery, and they gradually returned to normal size during follow-up after three doses of GnRH agonists, which validated our method.

In conclusion, hyperstimulated, enlarged ovaries and their complications could be persistent during and even after pregnancy when IVF is involved. The risks of malignancy and torsion must be kept in mind, but should not lead to unnecessary surgery. Long-term follow-up of IVF patients is recommended.

\footnotetext{
Abbreviations

ART: Assisted reproduction technology; DHEA: Dehydroepiandrosterone; E2: Estradiol; FSH: Follicle-stimulating hormone; FT4: Free thyroxine; GnRHa: Gonadotropin-releasing hormone agonist; IVF: In vitro fertilization; LH: Luteinizing hormone; OHSS: Ovarian hyperstimulation syndrome; P: Progesterone; PCOS: Polycystic ovarian syndrome; PRL: Prolactin; T: Testosterone; T4: Thyroxine; TSH: Thyroid-stimulating hormone; UFC: Urinary-free cortisol; VEGF: Vascular endothelial growth factor; $\beta$ hCG: Human chorionic gonadotropin
}

\section{Acknowledgments}

The authors thank the patient for agreeing to the publication of the case and are grateful to their colleagues who helped in the preparation of the manuscript.

\section{Availability of data and materials \\ The datasets used during the current study are available from the corresponding author on reasonable request.}

\section{Authors' contributions}

$\mathrm{SJ}, \mathrm{TQ}, \mathrm{SA}$, and $\mathrm{CR}$ discussed the treatment protocol and performed the surgery. $\mathrm{RX}$ contributed to the pathology of ovarian tissue. All authors contributed to the drafting and critical revision of the manuscript. All authors read and approved the final manuscript.

\section{Ethics approval and consent to participate}

Approval was obtained from the Institutional Review Board (IRB) of Peking Union Medical College Hospital for publishing this case report.

\section{Consent for publication}

Informed consent was obtained from the patient for publication of this case report and any accompanying images.

\section{Competing interests}

The authors declare that they have no competing interests.

\section{Publisher's Note}

Springer Nature remains neutral with regard to jurisdictional claims in published maps and institutional affiliations.

\section{Author details}

'Department of Obstetrics and Gynecology, Peking Union Medical College Hospital (PUMCH), Peking Union Medical College, Chinese Academy of Medical Science, Beijing 100730, People's Republic of China. ${ }^{2}$ Department of Pathology, Peking Union Medical College Hospital (PUMCH), Peking Union Medical College, Chinese Academy of Medical Science, Beijing, People's Republic of China.

Received: 2 May 2018 Accepted: 27 August 2018

Published online: 10 September 2018

\section{References}

1. Kumar P, Sait SF, Sharma A, Kumar M. Ovarian hyperstimulation syndrome. J Hum Reprod Sci. 2011;4:70-5.

2. Gera PS, Tatpati LL, Allemand MC, Wentworth MA, Coddington CC. Ovarian hyperstimulation syndrome: steps to maximize success and minimize effect for assisted reproductive outcome. Fertil Steril. 2010;94:173-8.

3. Nastri CO, Teixeira DM, Moroni RM, Leitão VM, Martins WP. Ovarian hyperstimulation syndrome: pathophysiology and prevention. J Assist Reprod Genet. 2010;27:121-8.

4. Grossman LC, Michalakis KG, Browne H, Payson MD, Segars JH. The pathophysiology of ovarian hyperstimulation syndrome: an unrecognized compartment syndrome. Fertil Steril. 2010;94:1392-8.

5. Haimov-Kochman R, Yanai N, Yagel S, Amsalem H, Lavy Y, Hurwitz A. Spontaneous ovarian hyperstimulation syndrome and hyperreaction luteinalis are entities in continuum. Ultrasound Obstet Gynecol. 2004; 24:675-8

6. Badawy A, Elnashar A. Treatment options for polycystic ovary syndrome. Int J Womens Health. 2011;3:25-35.

7. Romito I, Gulino FA, Lsgana AS, et al. Renal and hepatic functions after a week of controlled ovarian Hyperstimulation during in vitro fertilization cycles. Int J Fertil Steril. 2017;11:15-9.

8. Hakoun AM, AbouAl-Shaar I, Zaza KJ, Abou-Al-Shaar H, Salloum MA. Adnexal masses in pregnancy: an updated review. Avicenna J Med. 2017;7:153-7.

9. Habek D, Bauman R, Kralj LR, Hafner T, Turudic T, Vujisic S. Acute abdomen in the $17^{\text {th }}$ week of twin pregnancy due to ovarian torsion - a late complication of IVF. Geburtshilfe Frauenheilkd. 2016;76:1345-9.

10. Pearl J, Price R, Richardson W, Fanelli R. Society of American Gastrointestinal Endoscopic Surgeons. Guidelines for diagnosis, treatment, and use of laparoscopy for surgical problems during pregnancy. Surg Endosc. 2011;25: 3479-92. 
11. Krishnan S, Kaur H, Bali J, Rao K. Ovarian torsion in infertility managementmissing the diagnosis means losing the ovary: a high price to pay. J Hum Reprod Sci. 2011;:39-42.

12. Ling SY, Chong KM, Hwang JL. Persistent megalocystic ovary following in vitro fertilization in a postpartum patient with polycystic ovarian syndrome. Taiwan J Obstet Gynecol. 2006:45:70-2.

13. Alptekin H, Gezginç K, Yılmaz FY. Bilateral megalocystic ovaries following in vitro fertilization detected during cesarean section: a case presentation. J Turk Ger Gynecol Assoc. 2012;13:142-4.

14. Comba C, Ugurlucan FG, Bastu E, lyibozkurt AC, Topuz S. Persistent ascites resolving with gonadotropin-releasing-hormone-agonist 18 months after hospitalization for severe ovarian hyperstimulation syndrome. Arch Gynecol Obstet. 2014;289:223-5.

Ready to submit your research? Choose BMC and benefit from:

- fast, convenient online submission

- thorough peer review by experienced researchers in your field

- rapid publication on acceptance

- support for research data, including large and complex data types

- gold Open Access which fosters wider collaboration and increased citations

- maximum visibility for your research: over $100 \mathrm{M}$ website views per year

At BMC, research is always in progress.

Learn more biomedcentral.com/submissions 